\title{
Sociodemographic disparities and contextual factors in obesity: updated evidence from a National Survey of Risk Factors for Chronic Diseases
}

\author{
Sonia Alejandra Pou ${ }^{1,2}$, Maria Del Pilar Diaz ${ }^{1,2}$, Guillermo Angel Velázquez ${ }^{3}$ and \\ Laura Rosana Aballay ${ }^{2, *}$ \\ 'Instituto de Investigaciones en Ciencias de la Salud (INICSA), Universidad Nacional de Córdoba, Consejo Nacional \\ de Investigaciones Científicas y Técnicas (CONICET), Facultad de Ciencias Médicas, Córdoba, Argentina: \\ ${ }^{2}$ Estadística y Bioestadística, Escuela de Nutrición, Facultad de Ciencias Médicas, Universidad Nacional de Córdoba, \\ Córdoba 5016, Argentina: ${ }^{3}$ nstituto de Geografía, Historia y Ciencias Sociales (IGEHCS), Consejo Nacional de \\ Investigaciones Científicas y Técnicas (CONICET), Universidad Nacional del Centro de la Provincia de Buenos Aires, \\ Tandil, Buenos Aires, Argentina
}

Submitted 25 August 2020: Final revision received 14 December 2021: Accepted 16 December 2021: First published online 20 December 2021

\begin{abstract}
Objective: To assess the association of sociodemographic and environmental factors with the obesity occurrence in Argentina from a sex- and age-comparative perspective and a multilevel approach.

Design: Cross-sectional study based on secondary data from the National Survey of Chronic Diseases Risk Factors (CDRF) 2018, Argentina. Two-level logistic regression models stratified by sex and age were used.

Setting: The nationwide probabilistic sample of the CDRF survey and twenty-four geographical units.

Participants: 16410 adult people, living in Argentine towns of at least 5000 people, nested into 24 geographical units. Sex and age groups were defined as young (aged 18-44 years), middle-aged (45-64 years) and older (65 years and older) men and women.

Results: Single men (all age groups) and divorced/widowed men (aged 45 years or older) had a lower obesity risk compared to married ones. In the middle-aged group, men with higher education showed a lower risk than men with incomplete primary education. In young women, a marked social gradient by educational level was observed. A low-income level coupled with highly urbanised contexts represents an unfavourable scenario for young and middle-aged women. Having a multi-person household was a risk factor for obesity $(\mathrm{OR}=1.26, P=0.038)$ in middle-aged women. Contextual factors linked to the availability of socially constructed recreational resources and green spaces were associated with obesity among young adults.

Conclusions: Socio-environmental determinants of obesity seem to operate differently according to sex and age in Argentina. This entails the need to address the obesity epidemic considering gender inequalities and the socio-environmental context at each stage of life.
\end{abstract}

Keywords

Overweight

Multilevel analysis

Nutrition surveys

Built environment
Obesity, defined as abnormal or excessive fat accumulation that may impair health ${ }^{(1)}$, is a major public health concern worldwide. The obesity epidemic, although widespread, has been defined as complex in the Latin America and the Caribbean region, where both occurrence and trends vary within the territory and across social groups ${ }^{(2-4)}$. In Argentina, official reports show that the obesity prevalence in the urban adult population has risen from $14.6 \%$ in 2005 to over $25 \%$ in 2018 .

Epidemiological research on obesity has traditionally focused on the role of individual-level behavioural factors (diet and physical activity, mainly). Subsequently, greater attention has been paid to social and contextual influences on obesity, since the notions of 'obesogenic 
environments ${ }^{(5,6)}$, and 'nutrition transition ${ }^{(7,8)}$, have gradually consolidated.

In particular, the process of nutritional transition implies remarkable shifts in physical activity and diets of the populations with a rapid increase in the prevalence of overweight and obesity. These nutritional changes occur in the context of broader societal drivers (such as sociodemographic changes linked to urbanicity and a rapid economic development), which could mediate differential exposure to the causes of all forms of malnutrition ${ }^{(9)}$. The Social Determinant of Health approach ${ }^{(10)}$ explains that attitudes, beliefs or behaviours represent only the most downstream determinants in the causal pathways influencing health, which are shaped by more upstream determinants; overall, they reflect the economic and social resources and opportunities for improving health ${ }^{(11)}$. Specifically, it has been explained that the upstream determinants that influence obesogenic behaviours may simultaneously manifest as the form of tangible characteristics in the built or natural environments (which determine what is available), as well as less tangible features in our economic, political and sociocultural environments ${ }^{(12)}$. Based on this framework, we assumed that upstream social factors underlie obesity-related behaviours. Additionally, from a multilevel perspective ${ }^{(13)}$, we recognise that certain contextual characteristics of the built and natural environments (defined at a higher level) could operate together with certain individual social features (related to structural mechanisms of social stratification such as income, education, occupation and sex $)^{(10)}$ as socio-environmental factors related to obesity occurrence (defined at a lower level). Especially in developing countries, there is a lack of understanding about the simultaneous individual- and contextual-level factors that drive regional and other subnational disparities (e.g. by sexes and age groups) in obesity burden.

Overall, estimates indicate that the age patterns of obesity differ between men and women ${ }^{(14)}$. Although the ways in which the nutrition transition affects the diets of age groups differently is not well described in the scientific literature, it is recognised that several dimensions of social disadvantage exert differential effects across the life course, impacting on food security and, in turn, on body composition or nutritional status ${ }^{(15)}$. It has been suggested that, for example, the capacity to resist adverse societal influences could play a role in the result of malnutrition - including overweight $^{(9)}$, which could be important among more socially vulnerable population groups (possibly elderly or young women). However, the evidence on the mechanisms explaining age- and sex-related social disparities in obesity is still unclear. In the Latin American and the Caribbean region, the differentials by age groups deserve special attention given their ongoing and accelerated process of demographic ageing ${ }^{(16)}$.

In Argentina, updated and further contextualised evidence is needed to identify socio-environmental determinants of obesity by specific population groups at a national scale. Most of the national population-level studies on adult obesity cover up to the year $2013^{(17,18)}$; other works on lifestyles and sociodemographic factors related to obesity in this country, though interesting, do not have national representativeness ${ }^{(18-21)}$. Interestingly, some studies have identified diverse socio-environmental patterns and demographic factors accounting for the sex-specific geographical pattern on obesity-related chronic diseases in this country ${ }^{(22,23)}$. Thus, areas with higher mortality risk of CVD in men have been directly associated with the smallest urban scale coupled with a higher level of poverty, in contrast to the effect observed for women ${ }^{(22)}$. Besides, specific geographical patterns with disadvantageous socio-environmental features were identified in Argentina accounting for the differential burden of cancer mortality between sexes in this country ${ }^{(23)}$.

The National Survey of Chronic Diseases Risk Factors (CDRF) has been conducted every 4-5 years since 2005 in Argentina from a probabilistic population-based sample. This survey includes sociodemographic and health information from an urban target population aged 18 years or older living in Argentine towns with at least 5000 people. For the first time, the 2018 edition of this survey included anthropometric measurements (not self-reported data, as previously); the present study analyses the obesity scenario using this representative country dataset. To our knowledge, ours is the first research work that examines up-todate information on obesity in this country to explain social disparities and contextual factors underlying obesity distribution among different population groups by sex and age. In this population-based study, we assessed the association of individual-level social characteristics and environmental factors, simultaneously, with the obesity occurrence, using a multilevel modelling strategy over the latest available CDRF survey, 2018.

\section{Methods}

\section{Study design and data sources}

This study is based on secondary data collected from the CDRF survey carried out in 2018 by the National Health Ministry of Argentina and the National Institute of Statistics and Census (known by its acronym in Spanish, INDEC). The CDRF is a nationally representative face-toface survey conducted by trained interviewers, based on a rigorous probabilistic sampling design. The 2018 survey included anthropometric measurements of height and weight taken by trained health personnel. The instruments (portable electronic weighing scale and portable height measuring board) and the techniques used for the height and weight measurements follow the STEPS protocol of the $\mathrm{WHO}^{(24)}$ endorsed by the Ministry of Health and Social Development of the Nation, Argentina. 
The 2018 CDRF databases consist of a population-based sample of 29224 persons aged 18 years and older living in towns of at least 5000 people of Argentina. The sampling design of the CDRF was probabilistic and multistage. At the first stage, sampling selection was based on the Master Urban Sample of Dwellings of the Argentine Republic (MUDAR). The MUDAR has a complex sample design and is used by the INDEC as a framework for the selection of private dwellings for all its national surveys. In the CDRF, sampling units were selected from the MUDAR list by means of a stratified probabilistic design (by sociodemographic variables) and a systematic sampling (proportional to the total number of occupied dwellings). For the definitive sample of dwellings in the CDRF, a systematic selection of segments of five contiguous dwellings (within the MUDAR list and cartography) was applied to obtain the final sample of dwellings. At the survey moment, the interviewer selected with equal probability a person aged 18 years or older, assisted by a random algorithm. The final size of the sample was 29224 individuals for the application of the first part of the questionnaire (selfreported data), covering all jurisdictions in the country. For the second step that includes anthropometric measurements, a probabilistic subsample was made with $75 \%$ of previously selected dwellings (n 16577 individuals). More methodological details of the CDRF survey have been published in official reports of the National Health Ministry ${ }^{(25)}$.

In our study, a subset of 16410 persons with anthropometric measurements was extracted, after excluding 167 observations with incomplete data. For multilevel analyses, the individual-level dataset ( $n 16410$ ) was nested into the area-level information about environmental characteristics (n 24 geographical units, corresponding to administrative divisions). Two area-level variables were selected: the index of socially constructed recreational resources (SCRR) and the index of green spaces. The SCRR index is a score (calculated at provincial scale) that considers the availability of certain environmental conditions and cultural attractions such as urban aesthetics, urban heritage sites, cultural centres, shopping malls, sports centres, among others. The green space index (score) represents the availability of green spaces measured through land coverage by open green spaces or natural areas. Both indexes were part of the latest available Quality of Life Index database ${ }^{(26)}$, which incorporates data for Argentina at the county level from several sources (official reports, field studies and satellite imagery) into a Geographic Information System. This dataset and its methodological aspects were published elsewhere ${ }^{(23,26)}$.

\section{Statistical analyses: multilevel modelling}

Due to the hierarchical structure (spatial clustering) of the data (16 410 subjects nested into 24 geographical units), two-level logistic regression models were used to estimate the association between selected individual- and area-level covariables and obesity occurrence (dichotomous outcome, yes/no). Three age groups were defined as young (aged 18-44 years), middle-aged (aged 45-64 years) and older (65 years and older) considering the criteria of the INDEC and the MeSH descriptor of middle-aged provided by the US National Library of Medicine ${ }^{(27)}$. Thus, the sex and age groups defined were set up as strata in multilevel model adjustments. Obesity was defined as having a BMI $\geq 30$ (yes/no) following the WHO criterion $^{(1)}$. BMI was calculated by using measured anthropometric data.

The analyses were performed in sequential steps, from a variance component model (multilevel 'empty' model, without covariates) to an adjusted two-level model that included all the individual- and area-level variables. Model selection was based on the Akaike information criterion as well as the interpretability and comparability of results among the different population groups. Several individual-level variables that inform about sociodemographic characteristics of participants were considered in the models: marital status (married; divorced/ widowed; single), household type (one-person household; a couple without children; multi-person household including a couple with children or other persons at home), education (highest level of education attained: incomplete primary education or lower; primary education; high school; higher education), income level (higher, intermediate or lower if self-reported incomes are at the highest, second-to-four or first quintile of the income distribution, respectively) and geographic location of residence (city of residence classified by population size as: small cities of 5000-149999 people, or big/middle-sized cities of 150000 or more people). Since previous findings have indicated a joint effect of poverty and urbanisation on health statistics in Argentina ${ }^{(16)}$, additive interaction terms between income and geographic location were also considered. Finally, lifestyle-related variables such as physical activity (intense/intermediate/low), tobacco consumption (non-smoker/former smoker/smoker), and fruit and vegetable consumption (above or below the five portions/ day recommendation by the Food Guide for the Argentine Population) ${ }^{(28)}$ were included as adjustment variables. These data were gathered by a structured questionnaire administered by trained personnel. This instrument included questions about tobacco consumption (current consumption frequency and previous consumption of at least 100 cigarettes, among others) and the usual frequency of fruit or vegetable intake (times/week and daily portions by self-report), and a section with the International Physical Activity Questionnaire (IPAQ) for physical activity assessment ${ }^{(29)}$.

The area-level variables included in the model were the aforementioned contextual indexes (continuous variables at the provincial scale) of SCRR and of green spaces; both were calculated as population size-weighted average of the indexes reported at the county level ${ }^{(26)}$. The highest values 
for these indexes reflect the best situation of the availability of SCRR or green spaces.

The linear predictor of the general mixed logistic model was

$$
\begin{aligned}
\operatorname{logit}\left[E\left(y_{i j}\right)\right]= & \left(\beta_{0}+\xi_{\mathrm{j}}\right)+\beta_{1} \times_{1 i j}+\ldots+\beta_{p} x_{p i j}+\delta_{01} w_{1 j} \\
& +\ldots+\delta_{01} w_{l j},
\end{aligned}
$$

where $\mathrm{y}_{i j}$ is the response variable (obesity yes/no), $\mathrm{x}_{1 i j}$ to $\mathrm{x}_{p i j}$ and $w_{1 j}$ to $w_{l j}$ are explanatory variables with fixed effects (linear coefficients), corresponding to the individual- or area-level covariates, respectively. The term $\xi_{j}$ is a random intercept term representing the clustering variance structure and, therefore, accounting for the geographical variability in the estimation process. All models were adjusted by lifestyle-related variables. Thus, female-only and male-only models were fixed and the estimated association measures (OR) plotted. Then, six models were constructed for each sex and age group combination (young, middle-aged, and older men and women). All analyses were performed using Stata v14.

\section{Results}

This study examined the obesity occurrence among 16410 adult people (58\% women and $42 \%$ men) living in Argentina, using data from the CDRF survey. In 2018, over half $(51.0 \%)$ of the participants were young adults, and about $30.1 \%$ and $18.9 \%$ were middle-aged and older adults, respectively.

Table 1 presents the individual-level characteristics of the study participants, for the total sample and stratified according to age group and sex. As shown, about $46.8 \%$ of the participants reported a low level of physical activity, reaching values of $54.7 \%$ and $61.8 \%$ in older men and women, respectively. The percentage of people with low fruit and vegetable intake was around $90 \%$ in all age groups and both sexes. The percentage of smokers ( $21.8 \%$ in whole sample) was higher in men than women, especially in those under 65 years of age. In older adults, the percentage of former smokers was more than double in males (45.4\%) compared with the female group (19.4\%). Most participants were married ( $49.5 \%)$ and lived in a multi-person household (61.2\%). However, the distribution of subjects by marital status or household type shows differences between sexes. These differences were stronger in the elderly and were particularly related to the categories married or divorced (marital status variable), and one-person household (household-type variable). About $36 \%$ of the total sample had completed primary education (with higher prevalence in men than women, especially in the 18-44 years age group), while $17.3 \%$ reported having higher education. In all age groups, the percentage of people with higher education was higher in women than in men. Over half $(59.9 \%)$ of the participants had an intermediate income level. Particularly at higher-income levels, men always show higher values (\%) compared to women, being the difference more noticeable in younger groups. Regarding geographical location, approximately 55-60\% of participants from all age group and both sexes lived in big/middle-sized cities (Table 1).

A similar distribution across sex and age groups was found for area-level variables. In the whole sample, $33.9 \%$ and $55.1 \%$ lived in areas with high indexes (above the mean values) of the SCRR and green spaces, respectively. The mean (SD) score was $6.30(0.76)$ for SCRR index and $1.65(0.63)$ for green spaces, with maximum/minimum values of 4.96/9.00 and 0.67/2.94, respectively.

Participants (in the whole sample, regardless of sex) were homogeneously distributed across the categories of normal weight (30.6\%), pre-obesity (34.6\%) and obesity $(33.3 \%)$, with just $1.5 \%$ of people with underweight (Table 1). Underweight was more prevalent in younger groups, and especially among young women (2.9\%). Over $65 \%$ of the total participants $(71.4 \%$ in men and $65.2 \%$ in women) had a BMI of 25 or more (pre-obesity or obesity) (Table 1). Figure 1 presents the weight status distribution by sex and age group. As this figure shows, the most frequent category of the weight status was preobesity (BMI 25-29.9) in men (all age groups) and obesity $(\mathrm{BMI} \geq 30)$ in women (middle-aged and older age groups). In the whole sample, obesity prevalence was $33 \cdot 3 \%$. Both in men and women, the higher values were concentrated in middle-aged groups (Table 1). However, there were differences in obesity prevalence between sexes, mainly among older adults ( $41.9 \% v 36.9 \%$ in women and men aged 65 years or more, respectively) (Table 1). Figure 2 depicts the adjusted OR of obesity estimated by the femaleor male-only multilevel models (for all ages together). Middle-aged adults were 1.7 to 2 times more at risk of having obesity than young men or women. The elderly category also showed a similar OR (1.8) in women. Other individual-level characteristics such as living as a couple or in a multi-person household, and living in a small city with a lower-income level, showed opposite tendencies in women (direct association with obesity) and men (inverse association). A lower obesity risk of being divorced/widowed or single ( $v$. married) was found. In both sexes, there was a social gradient of the education level (people who are more advantaged in terms of education had lower obesity risk than those who are less advantaged); however, the risk reduction at higher educational level was stronger in women than men. Furthermore, higher SCRR and green spaces indexes were inversely associated with obesity in both groups (Fig. 2).

Although Figure 2 shows that differences between sexes, without discrimination by age group, are slight, interesting results emerged when analyses were performed by sex and age groups. Crude and adjusted OR estimates by multilevel models stratified by age group among men 


\section{NS Public Health Nutrition}

Table 1 Individual-level characteristics by age group and sex among 16410 adults. National Survey of Chronic Diseases Risk Factors, Argentina 2018

\begin{tabular}{|c|c|c|c|c|c|c|c|c|c|c|c|c|c|c|c|c|c|c|}
\hline & \multicolumn{8}{|c|}{ Men } & \multicolumn{8}{|c|}{ Women } & \multicolumn{2}{|c|}{ Both sexes } \\
\hline & \multicolumn{2}{|c|}{$\begin{array}{c}\text { Young men (aged } \\
\text { 18-44 years) } \\
n 3657\end{array}$} & \multicolumn{2}{|c|}{$\begin{array}{c}\text { Middle-aged men } \\
\text { (aged 45-64 years) } \\
n 2103\end{array}$} & \multicolumn{2}{|c|}{$\begin{array}{l}\text { Older men (65 years } \\
\text { or more) } n 1200\end{array}$} & \multicolumn{2}{|c|}{$\begin{array}{l}\text { Total adult men } \\
\quad n 6960\end{array}$} & \multicolumn{2}{|c|}{$\begin{array}{l}\text { Young women (aged 18- } \\
44 \text { years) } n 4714\end{array}$} & \multicolumn{2}{|c|}{$\begin{array}{c}\text { Middle-aged women } \\
\text { (aged 45-64 years) } \\
\quad n 2839\end{array}$} & \multicolumn{2}{|c|}{$\begin{array}{c}\text { Older women (65 } \\
\text { years or more) } \\
n 1897\end{array}$} & \multicolumn{2}{|c|}{$\begin{array}{l}\text { Total adult women } \\
\quad n 9450\end{array}$} & \multicolumn{2}{|c|}{$\begin{array}{l}\text { Total adult popula- } \\
\text { tion } n 16410\end{array}$} \\
\hline & Subjects & $\begin{array}{c}\% \text { by } \\
\text { columns* }\end{array}$ & Subjects & $\begin{array}{l}\text { \% by } \\
\text { columns* }\end{array}$ & Subjects & $\begin{array}{l}\text { \% by } \\
\text { columns* }\end{array}$ & Subjects & $\begin{array}{c}\% \text { by } \\
\text { columns* }\end{array}$ & Subjects & $\%$ by columns* & Subjects & $\begin{array}{l}\text { \% by } \\
\text { columns }^{*}\end{array}$ & Subjects & $\begin{array}{c}\% \text { by } \\
\text { columns* }\end{array}$ & Subjects & $\begin{array}{c}\text { \% by } \\
\text { columns }^{\star}\end{array}$ & Subjects & $\begin{array}{l}\text { \% by } \\
\text { columns* }\end{array}$ \\
\hline \multicolumn{19}{|l|}{ Individual-level characteristics } \\
\hline \multirow{2}{*}{\multicolumn{19}{|c|}{$\begin{array}{l}\text { Anthropometric characteristics } \\
\text { Weight status by BMlt }\end{array}$}} \\
\hline & & & & & & & & & & & & & & & & & & \\
\hline Underweight & 70 & 1.9 & 4 & 0.2 & 7 & 0.6 & 81 & $1 \cdot 2$ & 135 & 2.9 & 23 & 0.8 & 12 & 0.63 & 170 & 1.8 & 251 & 1.5 \\
\hline Normal weight & 1303 & 35.6 & 362 & 17.2 & 242 & $20 \cdot 2$ & 1907 & 27.4 & 2000 & 42.4 & 683 & 24.1 & 427 & 22.5 & 3110 & 32.9 & 5017 & 30.6 \\
\hline Pre-obesity & 1363 & 37.3 & 878 & $41 \cdot 7$ & 508 & $42 \cdot 3$ & 2749 & 39.5 & 1355 & 28.7 & 915 & 32.2 & 663 & 34.9 & 2933 & $31 \cdot 0$ & 5682 & 34.6 \\
\hline Obesity & 921 & $25 \cdot 2$ & 859 & 40.8 & 443 & 36.9 & 2223 & 31.9 & 1224 & 26.0 & 1218 & 42.9 & 795 & 41.91 & 3237 & 34.2 & 5460 & 33.3 \\
\hline \multicolumn{19}{|l|}{ Lifestyles-related characteristics } \\
\hline \multicolumn{19}{|l|}{ Physical activity } \\
\hline Intense & 1042 & 28.5 & 344 & $16 \cdot 4$ & 119 & 9.9 & 1505 & 21.6 & 776 & 16.5 & 357 & 12.6 & 130 & 6.8 & 1263 & 13.4 & 2768 & $16 \cdot 9$ \\
\hline Intermediate & 1230 & 33.6 & 740 & $35 \cdot 2$ & 423 & $35 \cdot 2$ & 2393 & 34.4 & 1842 & 39.1 & 1028 & $36 \cdot 2$ & 577 & 30.4 & 3447 & 36.5 & 5840 & 35.6 \\
\hline Low & 1349 & 36.9 & 999 & 47.5 & 656 & 54.7 & 3004 & $43 \cdot 2$ & 2064 & 43.8 & 1434 & 50.5 & 1172 & 61.8 & 4670 & 49.4 & 7674 & 46.8 \\
\hline No response & 36 & 1.0 & 20 & 0.9 & 2 & 0.2 & 58 & 0.8 & 32 & 0.7 & 20 & 0.7 & 18 & 0.9 & 70 & 0.7 & 128 & 0.8 \\
\hline \multicolumn{19}{|l|}{ Fruit and vegetable consumption } \\
\hline$<5$ portions/day & 3377 & 92.3 & 1939 & 92.2 & 1078 & 89.8 & 6394 & 91.9 & 4331 & 91.9 & 2556 & $90 \cdot 0$ & 1699 & 89.7 & 8586 & 90.9 & 14980 & 91.3 \\
\hline 5 or more portions/day & 163 & 4.5 & 108 & 5.1 & 86 & 7.2 & 357 & 5.1 & 228 & 4.8 & 224 & 7.9 & 166 & 8.7 & 618 & 6.5 & 975 & 5.9 \\
\hline No response & 117 & 3.2 & 56 & 2.7 & 36 & 3.0 & 209 & 3.0 & 155 & 3.3 & 59 & 2.1 & 32 & 1.7 & 246 & 2.6 & 455 & 2.8 \\
\hline \multicolumn{19}{|l|}{ Tobacco consumption } \\
\hline Non-smoker & 1961 & 53.6 & 931 & $44 \cdot 3$ & 508 & $42 \cdot 3$ & 3400 & 48.8 & 3066 & 65.0 & 1804 & 63.5 & 1361 & 71.7 & 6231 & 65.9 & 9631 & 58.7 \\
\hline Former smoker & 595 & $16 \cdot 3$ & 597 & 28.4 & 545 & $45 \cdot 4$ & 1737 & $25 \cdot 0$ & 597 & 12.7 & 490 & 17.3 & 369 & 19.4 & 1456 & 15.4 & 3193 & 19.5 \\
\hline Smoker & 1101 & 30.1 & 575 & $27 \cdot 3$ & 147 & $12 \cdot 2$ & 1823 & $26 \cdot 2$ & 1051 & $22 \cdot 3$ & 545 & 19.2 & 167 & 8.8 & 1763 & 18.7 & 3586 & 21.8 \\
\hline \multicolumn{19}{|l|}{ Social characteristics } \\
\hline Marital status & & & & & & & & & & & & & & & & & & \\
\hline Married & 1724 & $47 \cdot 1$ & 1325 & 63.0 & 691 & $57 \cdot 6$ & 3740 & 53.7 & 2385 & 50.6 & 1453 & $51 \cdot 2$ & 545 & 28.7 & 4383 & 46.4 & 8123 & 49.5 \\
\hline Divorced or widowed & 185 & 5.1 & 454 & 21.6 & 404 & 33.7 & 1043 & $15 \cdot 0$ & 422 & 8.9 & 877 & 30.9 & 1147 & 60.5 & 2446 & $25 \cdot 9$ & 3489 & $21 \cdot 3$ \\
\hline Single & 1748 & $47 \cdot 8$ & 324 & $15 \cdot 4$ & 105 & 8.7 & 2177 & $31 \cdot 3$ & 1907 & 40.4 & 509 & 17.9 & 205 & $10 \cdot 8$ & 2621 & 27.7 & 4798 & 29.2 \\
\hline Household type & & & & & & & & & & & & & & & & & & \\
\hline One-person household & 678 & 18.5 & 525 & 25.0 & 442 & 36.8 & 1645 & 23.6 & 518 & 11.0 & 636 & 22.4 & 961 & 50.7 & 2115 & 22.4 & 3760 & 22.9 \\
\hline Couple without children & 393 & 10.7 & 437 & 20.8 & 461 & 38.4 & 1291 & 18.5 & 449 & 9.5 & 488 & $17 \cdot 2$ & 384 & $20 \cdot 2$ & 1321 & $14 \cdot 0$ & 2612 & 15.9 \\
\hline Multi-person household & 2586 & 70.7 & 1141 & $54 \cdot 3$ & 297 & 24.7 & 4024 & 57.8 & 3747 & 79.5 & 1715 & 60.4 & 552 & 29.1 & 6014 & 63.6 & 10038 & $61 \cdot 2$ \\
\hline Education (highest level of education att & ained) & & & & & & & & & & & & & & & & & \\
\hline Incomplete primary education or lower & 154 & $4 \cdot 2$ & 242 & 11.5 & 310 & $25 \cdot 8$ & 706 & 10.1 & 173 & 3.7 & 299 & 10.5 & 469 & 24.7 & 941 & $10 \cdot 0$ & 1647 & $10 \cdot 0$ \\
\hline Primary education & 1287 & $35 \cdot 2$ & 905 & 43.0 & 546 & $45 \cdot 5$ & 2738 & 39.3 & 1318 & 28.0 & 1053 & 37.1 & 797 & $42 \cdot 0$ & 3168 & 33.5 & 5906 & 36.0 \\
\hline High school & 1703 & 46.6 & 606 & 28.8 & 237 & 19.7 & 2546 & 36.6 & 2276 & 48.3 & 807 & 28.4 & 383 & $20 \cdot 2$ & 3466 & 36.7 & 6012 & 36.6 \\
\hline Higher education & 513 & 14.0 & 350 & 16.6 & 107 & 8.9 & 970 & 13.9 & 947 & 20.1 & 680 & 23.9 & 248 & 13.1 & 1875 & 19.8 & 2845 & 17.3 \\
\hline Income level (self-reported family income & & & & & & & & & & & & & & & & & & \\
\hline Lower level & 843 & $23 \cdot 0$ & 385 & $18 \cdot 3$ & 118 & 9.8 & 1346 & 19.3 & 1290 & 27.4 & 566 & 19.9 & 198 & 10.4 & 2054 & 21.7 & 3400 & 20.7 \\
\hline Intermediate level & 2082 & 56.9 & 1197 & 56.9 & 836 & 69.7 & 4115 & 59.1 & 2678 & 56.8 & 1667 & 58.7 & 1376 & 72.5 & 5721 & 60.5 & 9836 & 59.9 \\
\hline Higher level & 732 & $20 \cdot 0$ & 521 & 24.8 & 246 & 20.5 & 1499 & 21.5 & 746 & 15.8 & 606 & $21 \cdot 3$ & 323 & 17.0 & 1675 & 17.7 & 3174 & 19.34 \\
\hline
\end{tabular}


and women separately are displayed in Tables 2 and 3. After controlling for lifestyle covariates, it was found that compared to married men, single (in all age groups) and divorced/widowed men (in the older and middle-aged groups) had lower risk of obesity (Table 2). In the female-only model (Table 3), the association between obesity occurrence and being single (lower risk compared to married) was significant among young and middle-aged women. There was a direct association between obesity and living in a multi-person household ( $v$. one-person household) in middle-aged women $(\mathrm{OR}=1 \cdot 26, \mathrm{p}=0 \cdot 042)$. Besides, a social gradient by education level was accentuated in the young women group (Table 3). In particular, higher education showed a significant inverse association with obesity in all the age groups for women, as well as in middle-aged men (Tables 2 and 3). The association of income level, coupled to geographical location (interaction term), with obesity was significant only for women (Table 3). Specifically, we observed that the income level factor is not independent of geographical location among young and middle-aged women; in these population groups, a lower-income level coupled with a highly urbanised context seems to be an unfavourable scenario related to the obesity outcome. An inverse association with obesity was observed for SCRR and green space indexes (lower risk as score increases), which was significant in young groups of both sexes (Tables 2 and 3).

\section{Discussion}

This study provides an updated and comprehensive picture of the obesity burden and its socio-environmental determinants in the adult population of Argentina, considering the multilevel structure of the national information. In our work, the 2018 obesity prevalence was about 33\%, with figures higher than $40 \%$ for middle-aged groups (both sexes) and older women. For 2018, our findings indicate that the association of social and environmental factors with the obesity occurrence differ considerably across age and sex groups. In males, marital status emerges as an individual-level factor associated with obesity, and a high education level showed a significant association for the middle-aged group. In women, our findings suggest that the education level, having a multi-person household, and living in a highly urbanised context with a lowerincome level are key factors associated with obesity occurrence, with differences by age groups. Contextual indexes of SCRR and green spaces were associated with obesity, specifically in the younger groups of both sexes.

The 2018 CDRF survey collected both self-reported and measured anthropometric data of the adult population of Argentina. Compared to previous statistics from the CDRF survey about self-reported BMI, increasing rates of obesity were observed since $2005^{(30)}$. The 2018 CDRF report indicates that the prevalence of obesity obtained 


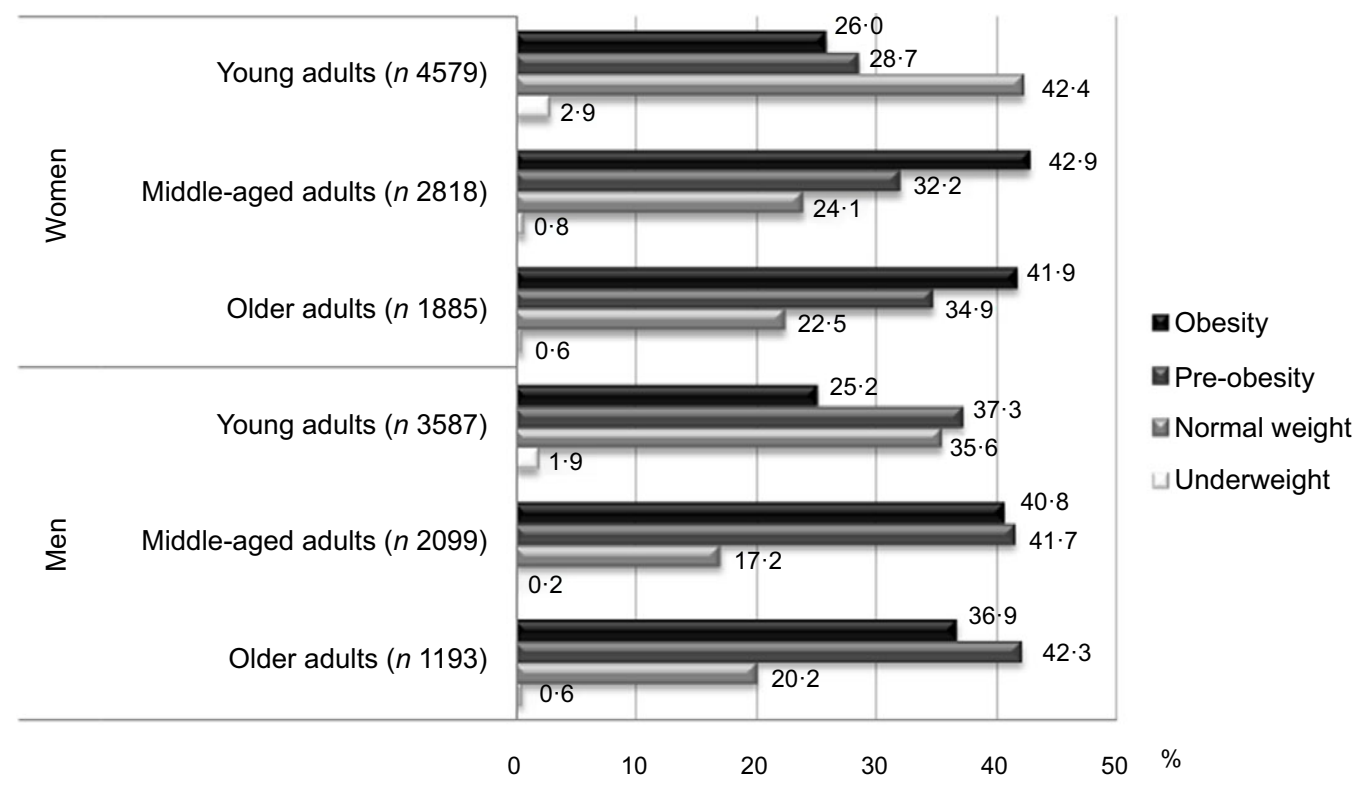

Fig. 1. Weight status distribution by age group based on a sample of 9450 women and 6960 men. National Survey of Chronic Diseases Risk Factors, Argentina 2018. Classification of weight status by measured BMI: underweight $(\mathrm{BMl}<18.5)$; normal weight (BMI 18.5-24.9); pre-obesity (BMI 25.0-29.9); and obesity (BMI $\geq 30)$

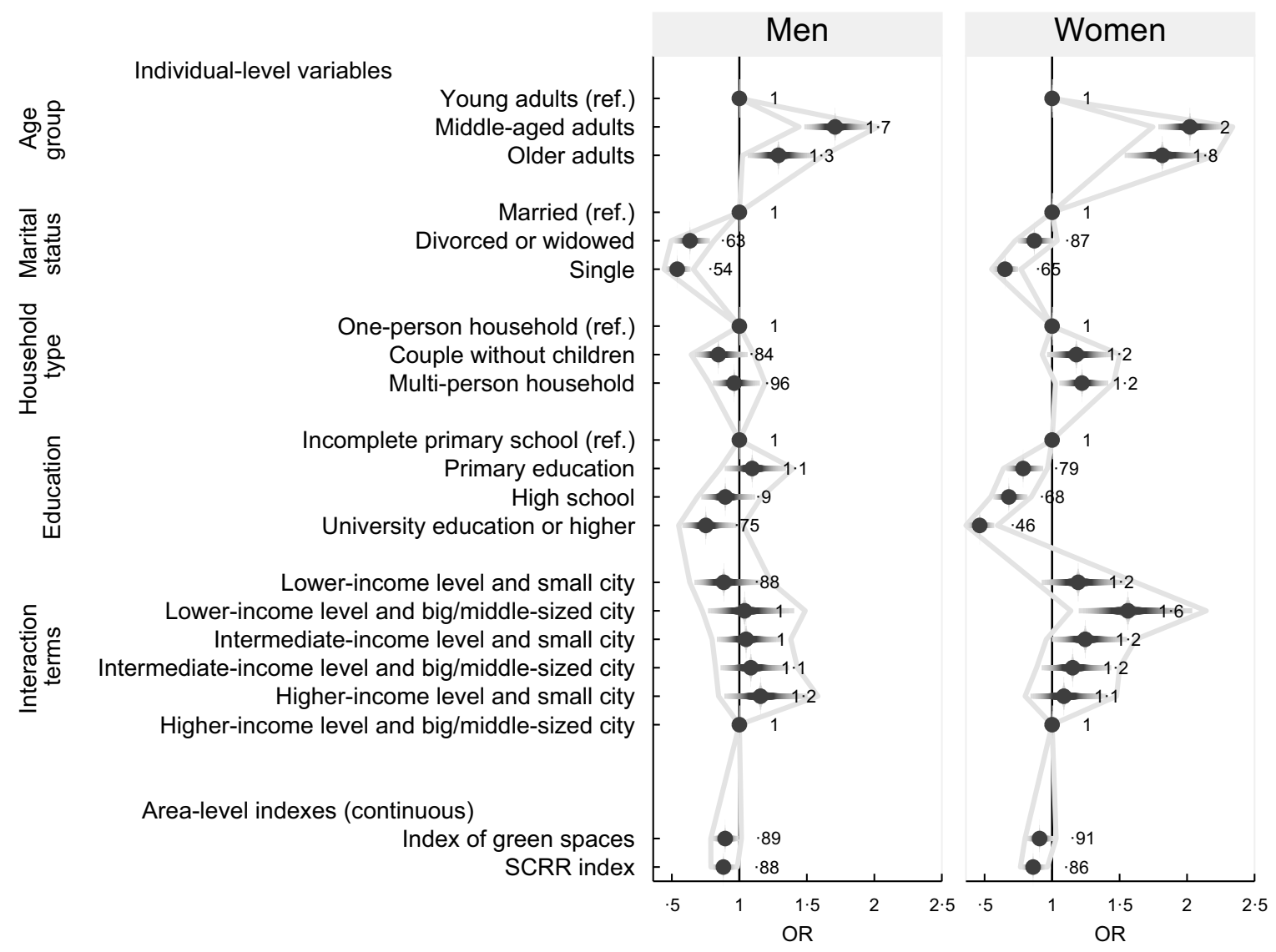

Fig. 2. Association between socio-environmental factors and obesity in Argentina: OR and Cl estimated by sex-specific models. Results from two-level logistic regression models with obesity (yes/no) as outcome, and provinces as clustering variable (random effect), adjusted by level of physical activity, tobacco, and fruit and vegetable consumption. National Survey of Chronic Diseases Risk Factors, Argentina, 2018. SCRR, SCRR, socially constructed recreational resources 


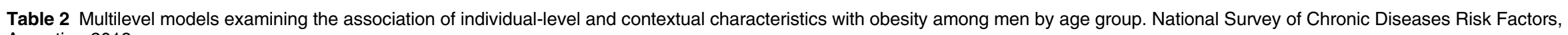
Argentina 2018

\begin{tabular}{|c|c|c|c|c|c|c|c|c|c|c|c|c|}
\hline \multirow[b]{3}{*}{ Covariable (fixed effects) } & & & & \multicolumn{9}{|c|}{ Male adult population of Argentina age-stratified multilevel models $\dagger$} \\
\hline & \multicolumn{4}{|c|}{ Young adults Model I } & \multicolumn{4}{|c|}{ Middle-aged adults Model II } & \multicolumn{4}{|c|}{ Older adults Model III } \\
\hline & OR crude $\ddagger$ & $\mathrm{OR}_{\mathrm{adj}} \S$ & $95 \% \mathrm{Cl}$ & $P$-value & OR crude $\ddagger$ & $\mathrm{OR}_{\text {adj. } .} \S$ & $95 \% \mathrm{Cl}$ & $P$-value & $\mathrm{OR}_{\text {crude }} \ddagger$ & $\mathrm{OR}_{\mathrm{adj} . \S}$ & $95 \% \mathrm{Cl}$ & $P$-value \\
\hline \multicolumn{13}{|l|}{ Individual-level social variables } \\
\hline \multicolumn{13}{|l|}{ Marital status } \\
\hline Married & 1 & 1 & - & - & 1 & 1 & - & - & 1 & 1 & - & - \\
\hline Divorced or widowed & 0.91 & 0.95 & $0.66,1.36$ & 0.768 & $0.63^{* *}$ & $0.64^{\star *}$ & $0.47,0.85$ & 0.003 & $0.55^{\star *}$ & $0.52^{\star \star}$ & $0.33,0.81$ & 0.004 \\
\hline Single & $0.47^{\star \star \star}$ & $0.52^{\star \star \star}$ & $0.43,0.62$ & $<0.001$ & $0.65^{\star \star}$ & $0.66^{\star}$ & $0.47,0.91$ & 0.011 & $0.54^{*}$ & $0.55^{*}$ & $0.31,0.98$ & 0.041 \\
\hline \multicolumn{13}{|l|}{ Household type: } \\
\hline One-person household & 1 & 1 & - & - & 1 & 1 & - & - & 1 & 1 & - & - \\
\hline Couple without children & 0.88 & 0.94 & $0.66,1.33$ & 0.734 & 0.78 & 0.74 & $0.51,1.05$ & 0.093 & 0.87 & 0.81 & $0.50,1.31$ & 0.394 \\
\hline Multi-person household & 1.09 & 1.15 & $0.90,1.47$ & 0.262 & 0.84 & 0.86 & $0.64,1.15$ & 0.310 & 0.79 & 0.78 & $0.51,1.19$ & 0.250 \\
\hline \multicolumn{13}{|l|}{ Education: } \\
\hline Incomplete primary education or lower & 1 & 1 & - & - & 1 & 1 & - & - & 1 & 1 & - & - \\
\hline Primary education & 1.06 & 0.12 & $0.75,1.66$ & 0.579 & 0.96 & 1.00 & $0.74,1.36$ & 0.981 & 1.07 & 1.11 & $0.82,1.51$ & 0.499 \\
\hline High school & 0.89 & 0.97 & $0.65,1.46$ & 0.901 & 0.77 & 0.75 & $0.55,1.08$ & 0.129 & 0.87 & 0.87 & $0.59,1.28$ & 0.481 \\
\hline Higher education & 0.72 & 0.78 & $0.49,1.23$ & 0.284 & $0.66^{*}$ & $0.68^{*}$ & $0.47,0.99$ & 0.049 & 0.86 & 0.83 & $0.50,1.40$ & 0.490 \\
\hline \multicolumn{13}{|l|}{ IL × geographic location: } \\
\hline Higher IL, big or middle-sized city & 1 & 1 & - & - & 1 & 1 & - & - & 1 & 1 & - & - \\
\hline Lower IL, small city & 1.08 & 1.06 & $0.72,1.57$ & 0.745 & 0.75 & 0.70 & $0.45,1.07$ & 0.097 & 0.97 & 0.93 & $0.48,1.81$ & 0.833 \\
\hline Lower IL, big or middle-sized city & 1.04 & 1.04 & $0.69,1.57$ & 0.841 & 1.39 & 1.35 & $0.85,2 \cdot 13$ & 0.203 & 0.50 & 0.55 & $0.25,1.19$ & 0.131 \\
\hline Intermediate IL, small city & $1 \cdot 34$ & $1 \cdot 30$ & $0.94,1.82$ & 0.113 & 1.00 & 0.93 & $0.66,1.31$ & 0.694 & 0.77 & 0.74 & $0.47,1.18$ & 0.205 \\
\hline Intermediate IL, big or middle-sized city & $1 \cdot 30$ & $1 \cdot 28$ & $0.92,1.79$ & 0.145 & 1.03 & 1.01 & $0.72,1.44$ & 0.932 & 0.79 & 0.80 & $0.50,1.26$ & 0.335 \\
\hline Higher IL, small city & $1 \cdot 10$ & 1.09 & $0.74,1.60$ & 0.653 & 1.18 & 1.14 & $0.78,1.67$ & 0.500 & 1.28 & 1.26 & $0.74,2 \cdot 14$ & 0.393 \\
\hline \multicolumn{13}{|l|}{ Area-level variables } \\
\hline SCRR index (continuous variable) & $0.84^{\star \star}$ & $0.84^{\star \star}$ & $0.74,0.95$ & 0.008 & 0.88 & 0.86 & $0.74,1.01$ & 0.075 & 0.97 & 0.97 & $0.81,1.15$ & 0.712 \\
\hline Index of green spaces (continuous variable) & 0.89 & $0.86^{*}$ & $0.75,0.98$ & 0.027 & 0.91 & 0.89 & $0.74,1.06$ & 0.192 & 1.04 & 1.00 & $0.81,1.25$ & 0.964 \\
\hline
\end{tabular}

IL, income level; SCRR, socially constructed recreational resources.

${ }^{\star} P<0.05,{ }^{\star *} P<0.01$, or ${ }^{* \star *} P<0.001$ as levels of significance.

†Two-level logistic regression model with provinces as clustering variable (random effect).

$\neq O R$ crude.

$\S \mathrm{OR}$ adjusted by level of physical activity, tobacco consumption, and fruit and vegetable consumption. 


\section{Neselic Health Nutrition}

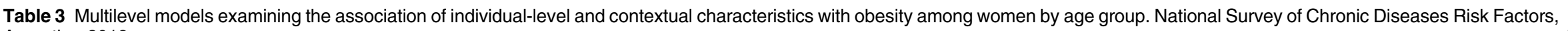
Argentina 2018

\begin{tabular}{|c|c|c|c|c|c|c|c|c|c|c|c|c|}
\hline \multirow[b]{3}{*}{ Covariable (fixed effects) } & & & & \multicolumn{9}{|c|}{ Female adult population of Argentina age-stratified multilevel models $\dagger$} \\
\hline & \multicolumn{4}{|c|}{ Young adults Model I } & \multicolumn{4}{|c|}{ Middle-aged adults Model II } & \multicolumn{4}{|c|}{ Older adults Model III } \\
\hline & $\mathrm{OR}_{\text {crude }} \ddagger$ & $\mathrm{OR}_{\mathrm{adj} . \S}$ & $95 \% \mathrm{Cl}$ & $P$ value & OR $_{\text {crude }} \ddagger$ & $\mathrm{OR}_{\text {adj } . \S}$ & $95 \% \mathrm{Cl}$ & $P$ value & OR crude $\neq$ & $\mathrm{OR}_{\mathrm{adj}} \S$ & $95 \% \mathrm{Cl}$ & $P$-value \\
\hline \multirow{2}{*}{\multicolumn{13}{|c|}{ Individual-level social variables }} \\
\hline \multicolumn{11}{|l|}{ Marital status: } & & \\
\hline Married & 1 & 1 & - & - & 1 & 1 & - & - & 1 & 1 & - & - \\
\hline Divorced or widowed & 1.05 & 1.08 & $0.85,1.37$ & 0.534 & 0.82 & 0.82 & $0.67,1.01$ & 0.069 & 0.91 & 0.86 & $0.60,1.23$ & 0.409 \\
\hline Single & $0.60^{* * *}$ & $0.62^{* \star *}$ & $0.53,0.73$ & $<0.001$ & 0.79 & $0.78^{*}$ & $0.61,0.99$ & 0.044 & 0.72 & 0.67 & $0.43,1.06$ & 0.087 \\
\hline \multicolumn{13}{|l|}{ Household type: } \\
\hline One-person household & 1 & 1 & - & - & 1 & 1 & - & - & 1 & 1 & - & - \\
\hline Couple without children & $1 \cdot 16$ & $1 \cdot 14$ & $0.81,1.62$ & 0.450 & 1.26 & 1.26 & $0.93,1.71$ & 0.133 & 1.19 & 1.14 & $0.74,1.74$ & 0.543 \\
\hline Multi-person household & $1 \cdot 23$ & $1 \cdot 23$ & $0.95,1.60$ & 0.120 & $1 \cdot 20$ & $1 \cdot 26^{*}$ & $1.01,1.57$ & 0.042 & $1 \cdot 14$ & $1 \cdot 17$ & $0.92,1.49$ & 0.205 \\
\hline \multicolumn{13}{|l|}{ Education: } \\
\hline Incomplete primary education or lower & 1 & 1 & - & - & 1 & 1 & - & - & 1 & 1 & - & - \\
\hline Primary education & $0.49^{\star \star \star}$ & $0.47^{\star * *}$ & $0.33,0.65$ & $<0.001$ & 0.83 & 0.86 & $0.66,1 \cdot 13$ & 0.292 & 0.82 & $0 \cdot 81$ & $0.64,1.03$ & 0.092 \\
\hline High school & $0.37^{\star \star \star}$ & $0.36^{\star \star \star}$ & $0.26,0.51$ & $<0.001$ & $0.73^{*}$ & 0.76 & $0.57,1.02$ & 0.071 & 0.91 & 0.92 & $0.68,1.23$ & 0.562 \\
\hline Higher education & $0.27^{\star \star \star}$ & $0.25^{\star \star \star}$ & $0.17,0.36$ & $<0.001$ & $0.44^{\star * \star}$ & $0.47^{\star * *}$ & $0.35,0.65$ & $<0.001$ & $0.67^{*}$ & $0.64^{*}$ & $0.44,0.92$ & 0.015 \\
\hline \multicolumn{13}{|l|}{ IL $\times$ geographic location: } \\
\hline Higher IL, big or middle-sized city & 1 & 1 & - & - & 1 & 1 & - & - & 1 & 1 & - & - \\
\hline Lower IL, small city & 1.35 & 1.25 & $0.86,1.83$ & 0.237 & 1.13 & 1.13 & $0.78,1.65$ & 0.511 & 1.03 & 1.15 & $0.66,2.00$ & 0.609 \\
\hline Lower IL, big or middle-sized city & $1 \cdot 63^{*}$ & $1.56^{*}$ & $1 \cdot 06,2 \cdot 30$ & 0.024 & $1 \cdot 61^{*}$ & $1 \cdot 67^{*}$ & $1.12,2.49$ & 0.012 & 1.48 & 1.64 & $0.91,2.95$ & 0.099 \\
\hline Intermediate IL, small city & $1.42^{*}$ & 1.35 & $0.96,1.91$ & 0.087 & 1.31 & 1.35 & $0.99,1.85$ & 0.058 & $1 \cdot 10$ & $1 \cdot 13$ & $0.75,1.70$ & 0.551 \\
\hline Intermediate IL, big or middle-sized city & 1.36 & $1 \cdot 27$ & $0.90,1.81$ & 0.175 & 1.11 & $1 \cdot 12$ & $0.81,1.54$ & 0.489 & 1.03 & 1.08 & $0.72,1.61$ & 0.713 \\
\hline Higher IL, small city & $1.48^{*}$ & 1.41 & $0.95,2.08$ & 0.086 & 1.02 & 1.02 & $0.71,1.46$ & 0.930 & 0.93 & 0.94 & $0.58,1.52$ & 0.798 \\
\hline \multicolumn{13}{|l|}{ Area-level variables } \\
\hline SCRR index (continuous variable) & $0.77^{\star \star \star}$ & $0.76^{\star \star \star}$ & $0.68,0.85$ & $<0.001$ & 0.89 & 0.90 & $0.77,1.04$ & 0.163 & 0.97 & 0.97 & $0.85,1.11$ & 0.674 \\
\hline Index of green spaces (continuous variable) & $0.86^{* *}$ & $0.85^{\star *}$ & $0.76,0.96$ & 0.007 & 1.03 & 1.02 & $0.87,1.21$ & 0.777 & 0.87 & 0.86 & $0.73,1.02$ & 0.094 \\
\hline
\end{tabular}

IL, income level; SCRR, socially constructed recreational resources.

${ }^{*} P<0.05,{ }^{* *} P<0.01$, or ${ }^{* \star *} P<0.001$ as levels of significance.

†Two-level logistic regression model with provinces as clustering variable (random effect).

$\ddagger O R$ crude.

$\S \mathrm{OR}$ adjusted by level of physical activity, tobacco consumption, and fruit and vegetable consumption. 
from measured data was about $7 \%$ point higher than those based on self-reported $\mathrm{BMI}^{(30)}$. The high levels of obesity estimated for Argentina in 2018 are consistent with the growing burden of obesity reported in the Latin American region $^{(3,14)}$. The changes in the nutritional profile of the Latin American populations in the last decades have largely been attributed to the process of the nutrition transition $^{(3)}$, which occurred in parallel with several socio-economic and demographic shifts (e.g. changes linked to the urbanisation and globalisation processes) in most regions of the world ${ }^{(8)}$. Interestingly, a recent study in Argentina reports that sociodemographic factors (such as urbanisation and poverty level) play a major role in shaping diverse nutritional profiles across the territory, which configure a complex and heterogeneous socio-nutritional scenario ${ }^{(17)}$.

Overall, existing studies about the association between marital status and overweight indicate that the former appears to influence obesity more strongly among men than women ${ }^{(31,32)}$. The lower obesity risk in single men has been reported by other studies ${ }^{(19,33,34)}$. This could be related to the lifestyle of married men that may lead to a more stable eating pattern, compared to unmarried people $^{(31)}$. Besides, a larger body size is likely to be valued as a sign of physical dominance and prowess for men ${ }^{(35)}$, if we consider the expected social roles for men entering marriage in some social groups. It is important to note that the lower obesity risk observed in single men in our study was also present among single females, particularly in the younger groups. In this case, this finding may reflect certain body weight norms and expectations in our society linked to the female beauty ideal, more solid at certain stages of life. An exaggerated thin body ideal has been recognised as a distinctive characteristic of the Argentine population $^{(36)}$, especially among women.

We also found a significantly lower risk for the divorced/ widowed category in the middle-aged and elderly men groups ( $v$. married). This could be explained, in part, by the fact that marital disruption (i.e. being widowed or divorced) has been associated with poor physical health outcomes $^{(32)}$, including weight loss linked to psychosocial frailty or high-risk alcohol or tobacco consumption. Additionally, it has been proposed that the marital role provides support and resources which may influence eating and physical activity habits ${ }^{(31)}$. Thus, the lower obesity risk observed for divorced/widowed men older than 44 years of age ( $v$. married ones) may indirectly reflect their potential lack of social support as observed, for example, in eating habits. The importance of social support for health is well recognised ${ }^{(37)}$, as well as the role of women as the ones mostly responsible for food preparation in families ${ }^{(35)}$. In Argentina, a national study on older adults highlights that women have a high physical and psychological burden associated with such activities as the care of elderly or family members ${ }^{(38)}$.

Education is a recognised individual-level socioeconomic factor related to obesity risk. Overall, there is a general agreement that the relationship between education and obesity is often more consistent among women ${ }^{(34,39,40)}$. Additionally, we found a stronger educational gradient in the obesity burden among the younger group of Argentine women. This finding is in line with previous studies carried out in this country in 2005 , which reported a lower obesity prevalence with better education level among women aged $20-49$ years $^{(41)}$. Also in other Latin American countries, lower obesity prevalence was observed in women with higher education among this age group ${ }^{(42,43)}$. Particularly from a longitudinal study, a reversal of the inverse association between education level and obesity risk during ageing was observed, especially in women. These authors propose that women with higher education put more effort than men into controlling their body weight, to fit themselves in the labour market and to reach a high social position; then, approaching old age, women try to get rid of the social pressures towards thinness ${ }^{(44)}$. A sociocultural pressure on females to achieve the desired body image, especially among women of high socio-economic status suggested by other authors ${ }^{(45)}$, can explain, in part, our findings in Argentina.

Since education has a role as part of the complex phenomenon of socio-economic stratification, another aspect to considerer is that people with higher education may have greater job opportunities and, therefore, better access to physical activity facilities and healthy eating. Furthermore, education can be interpreted as a proxy for 'health literacy ${ }^{\prime(39,40)}$, which could improve an individual's capacity to adequately address health-related issues, including overweight ${ }^{(40,46)}$. These could be underlying mechanisms that explain, in part, the relationship observed between obesity and higher education, especially in middle-aged men and elderly women.

It has been highlighted that socio-economic inequalities within cities in developing countries are high and affect the social distribution of health outcomes ${ }^{(47)}$. In Argentina, previous evidence indicates that the socio-economic patterning of chronic disease risk factors, including obesity, was modified by urbanicity ${ }^{(48)}$, and that poverty and urban scale are associated contextual variables influencing the distribution of non-communicable diseases mortality ${ }^{(22)}$. In our study, a higher risk of obesity was observed among women under 65 years of age living in big or middle-sized cities with a low family income level. Income generally reflects the availability of economic and material resources and, thus, it influences dietary quality ${ }^{(49)}$. These results may reflect poor access to a healthy diet and low opportunities to adopt healthy behaviours, in women with a low-income level, especially if they live in urbanised areas. Interestingly, Oliveira et al. ${ }^{(50)}$ indicated that there are several aspects (physical, economic, political and sociocultural) of the environmental factors that would independently affect men and women, and that obesogenic influence of the environment may differ in small and medium-sized cities, when compared to large cities. 
According to the $\mathrm{WHO}$, urban poverty and unhealthy living conditions themselves are social determinants of health that can affect disproportionately certain vulnerable subgroups such as women ${ }^{(51)}$. Moreover, considering their potential family caregiver role ${ }^{(38)}$, especially under unfavourable economic conditions, Argentine women may reduce their time for the care of their own health (impacting on their weight status). This could also explain, in part, the higher obesity risk in middle-aged women living in a multiperson household that we observed in our results.

Considering environmental factors, there is suggestive evidence about the relationship between green spaces and weight status or obesity-related health indicators. Several studies found evidence that these relationships varied by factors such as age and socio-economic status, although the mechanisms through which green spaces may influence health are not completely understood ${ }^{(52)}$. Evidence suggests that there is a link between green spaces and obesity, as the former would offer enhanced opportunities for physical activity ${ }^{(52,53)}$, even within urbanised contexts ${ }^{(54)}$. However, the findings on this matter are not conclusive, especially in developing countries. In Argentina, agriculture and tourism are motors of regional economic development; agricultural and touristic activities usually take place in locations where natural resources are highly available. Thus, we additionally argue that the environmental indicator used here may represent proxy variables of socio-economic conditions at the macro-level.

From a gendered perspective, MacBride-Stewart et $a l .{ }^{(55)}$ identify key dimensions to consider in the study of the interconnections between health and nature, including accessibility, availability and usability of green spaces, as well as the boundaries (symbolic/material) that construct differential relationships between natural spaces, sex and health ${ }^{(55)}$. Consistently, another work ${ }^{(56)}$ also indicates that the perception and use of green spaces, as well as green space attributes, can explain the different associations with BMI that the authors observed among ageand sex-specific adult groups. Given our finding of an association between area-level variables and obesity occurrence, those variables may also be relevant aspects to explain age group differences in Argentina.

Particularly, the role of the contextual conditions summarised in the SCRR index (such as urban aesthetics/urban heritage, cultural amenities, shopping malls and sports centres) is underexplored in obesity research. However, the notion of SCRR could be closely related to the idea of built environments, defined as the human-modified space in which people conduct their daily lives; their influence on obesity has been more extensively studied ${ }^{(57)}$. In general, there is consensus that the built environment plays a key role as a barrier or enabler to physical activity and as a mediator in access to healthy food ${ }^{(54,58)}$. Interestingly, an exhaustive review from the perspective of developing countries $^{(50)}$ concludes that health-promoting built environments can have a profound influence not only on the population levels of physical activity but also on its wellbeing and equity - both socio-economic and age-sensitive. Thus, our findings of a lower obesity risk associated with contexts with greater SCCR in young people could be related to a mechanism mediated by the availability, perception and use of sports centres or other amenities that were part of the SCRR index. In a Brazilian study on obesity, the authors reinforce the idea that a favourable decrease in 'obesogenic' traits in the urban environment is possible when physical structures are planned to facilitate physical $\operatorname{activity}^{(50)}$. Alternatively, we propose that the distribution of the SCRR variable could depict a sort of 'regionalisation' (geographical division) underlying socio-economic and cultural characteristics of the populations or could represent different patterns of land use. Consistent evidence showed that a better mix of land use (residential, commercial, institutional, industrial, recreational and agricultural) is generally associated with less obesity burden $^{(12)}$, although there is a general lack of insight into the pathway by which land use mix impacts obesity. Further research would be useful in these regards to better understand the observed age differences.

A major strength of this research is its updated source of data and large sample size based on a rigorous probabilistic sampling design which ensures its national representativeness. Indeed, the matching between the age group distribution in our sample and in the national population projections for 2018 by the INDEC is notable. Besides, as far as we know, this is the first study that uses measured anthropometric data to identify social inequalities in obesity distribution from the most recent CDFR survey. Moreover, it provides an analytical example of how the multilevel epidemiological framework can be used in this field of study. However, there are limitations to consider. First, we know that our study was based on an urban setting and, thus, rural populations were not represented. However, about $91 \%$ of the Argentine population is living in urban areas ${ }^{(22)}$. Second, the reliability of income measures may be debatable in developing countries ${ }^{(59)}$, although several questions regarding household income were designed to minimise response bias in the CDRF. Also the use of BMI as a measure of obesity could be discussed, since this index should be preferably accompanied by other body composition measures in some specific population groups, such as athletes and the elderly. However, the WHO recognises that BMI provides the most useful population-level measure of overweight and obesity ${ }^{(1)}$. Finally, considering that exposure measurement error may occur in the characterisation of green spaces in epidemiological studies ${ }^{(53)}$, and that other unmeasured macro-level factors may affect conclusions, the interpretation of macro-contextual association measures should be conservative.

To conclude, our findings show high levels of obesity in Argentina in 2018 and an unequal distribution of their socio-environmental determinants. Specific social and 
environmental factors seem to operate differently according to sex and age groups in this country. Thus, comprehensive interventions against the obesity epidemic addressing gender inequalities and socio-environmental disadvantages at each stage of life are needed. Our results also showed a favourable relationship (inverse association) between obesity risk and contextual characteristics (such as availability of green spaces) among the younger groups. This target population could be considered in the design of interventions aimed at achieving healthy environments. Finally, further interdisciplinary research on sociocultural pathways linked to obesity within urban contexts in developing countries is needed.

\section{Acknowledgements}

Acknowledgements: We thank Gabriela Díaz Cortez for her language assistance. Financial support: This work was supported by the Science and Technical Department of the University of Córdoba (grant number 33820180100195CB01). Conflict of interest: SAP, MPD, GAV and LRA confirm that there are no relevant financial or non-financial competing interests to report. Authorship: S. A. P., L. R. A. and G. A. V. contributed to the study conception and design. Data analysis was performed by S. A. P., L. R. A. and M. P. D. The first draft of the manuscript was written by S. A. P. L. R. A. and M. P. D. contributed to the writing of subsequent drafts of the manuscript. All authors contributed to the interpretation of results and have approved the final manuscript. Ethics of buman subject participation: This study was conducted according to the guidelines laid down in the Declaration of Helsinki, and all procedures involving research study participants were approved by the Ethical Committee of the Hospital Nacional de Clínicas, University of Córdoba, Argentina. Written informed consent was obtained from all subjects.

\section{References}

1. World Health Organization (2020) Obesity and Overweight. http://www.who.int/en/news-room/fact-sheets/detail/obe sity-and-overweight (accessed May 2020).

2. NCD Risk Factor Collaboration (2017) Worldwide trends in body-mass index, underweight, overweight, and obesity from 1975 to 2016: a pooled analysis of 2416 populationbased measurement studies in 128.9 million children, adolescents, and adults. Lancet 390, 2627-2642.

3. Popkin BM \& Reardon T (2018) Obesity and the food system transformation in Latin America. Obes Rev 19, 1028-1064.

4. Jiwani SS, Carrillo-Larco RM, Hernández-Vásquez A et al. (2019) The shift of obesity burden by socioeconomic status between 1998 and 2017 in Latin America and the Caribbean: a cross-sectional series study. Lancet Glob Health 7, e1644-e1654.
5. Kirk SF, Penney TL \& McHugh TL (2010) Characterizing the obesogenic environment: the state of the evidence with directions for future research. Obes Rev 11, 109-117.

6. Townshend T \& Lake A (2017) Obesogenic environments: current evidence of the built and food environments. Perspect Public Health 137, 38-44.

7. Popkin BM, Adair LS \& Ng SW (2012) Global nutrition transition and the pandemic of obesity in developing countries. Nutr Rev 70, 3-21.

8. Popkin BM (2006) Global nutrition dynamics: the world is shifting rapidly toward a diet linked with noncommunicable diseases. Am J Clin Nutr 84, 289-298.

9. Wells JC, Sawaya AL, Wibaek R et al. (2020) The double burden of malnutrition: aetiological pathways and consequences for health. Lancet 395, 75-88.

10. Solar O \& Irwin A (2010) A Conceptual Framework for Action on the Social Determinants of Health. Discussion Paper Series on Social Determinants of Health. Geneva: World Health Organization.

11. Braveman P, Egerter S \& Williams DR (2011) The social determinants of health: coming of age. Annu Rev Public Health 32, 381-398.

12. Lakerveld J \& Mackenbach J (2017) The upstream determinants of adult obesity. Obes Facts 10, 216-222.

13. Merlo J, Chaix B, Ohlsson H et al. (2006) A brief conceptual tutorial of multilevel analysis in social epidemiology: using measures of clustering in multilevel logistic regression to investigate contextual phenomena. $J$ Epidemiol Community Health 60, 290-297.

14. Ng M, Fleming T, Robinson M et al. (2014) Global, regional, and national prevalence of overweight and obesity in children and adults during 1980-2013: a systematic analysis for the Global Burden of Disease Study 2013. Lancet 384, 766-781.

15. Schrock JM, McClure HH, Snodgrass JJ et al. (2017) Food insecurity partially mediates associations between social disadvantage and body composition among older adults in india: results from the study on global AGEing and adult health (SAGE). Am J Hum Biol 29, e23033.

16. Palloni A, Pinto-Aguirre G \& Pelaez M (2002) Demographic and health conditions of ageing in Latin America and the Caribbean. Int J Epidemiol 31, 762-771.

17. Tumas N, Rodríguez Junyent C, Aballay LR et al. (2019) Nutrition transition profiles and obesity burden in Argentina. Public Health Nutr 22, 2237-2247.

18. Linetzky B, De Maio F, Ferrante D et al. (2013) Sex-stratified socio-economic gradients in physical inactivity, obesity, and diabetes: evidence of short-term changes in Argentina. Int J Public Health 58, 277-284.

19. Aballay LR, Osella AR, Celi A et al. (2009) Overweight and obesity: prevalence and their association with some social characteristics in a random sample population-based study in Córdoba city, Argentina. Obes Res Clin Pract 3, 75-83.

20. Aballay LR, Osella AR, De La Quintana AG et al. (2016) Nutritional profile and obesity: results from a random-sample population-based study in Córdoba, Argentina. Eur J Nutr 55, 675-685.

21. Pou SA, Del Pilar Díaz M, De La Quintana AG et al. (2016) Identification of dietary patterns in urban population of Argentina: study on diet-obesity relation in population-based prevalence study. Nutr Res Pract 10, 616-622.

22. Pou SA, Tumas N, Sánchez Soria D et al. (2017) Large-scale societal factors and noncommunicable diseases: urbanization, poverty and mortality spatial patterns in Argentina. Appl Geogr 86, 32-40.

23. Pou SA, Diaz MDP \& Velazquez GA (2018) Socio-environmental patterns associated with cancer mortality: a study based on a quality of life approach. Asian Pac J Cancer Prev 19, 3045-3052. 
24. World Health Organization (WHO), Noncommunicable Diseases \& Mental Health Cluster (2005) WHO STEPS Surveillance Manual: The WHO STEPwise Approach to Chronic Disease Risk Factor Surveillance. Geneva: WHO. https://apps.who.int/iris/handle/10665/43376 (accessed August 2021).

25. Instituto Nacional de Estadísticas y Censos (INDEC) (2020) Argentina. https://www.indec.gob.ar/indec/web/Instituci onal-Indec-BasesDeDatos-2 (accessed June 2020).

26. Velázquez G (2016) A new index for study Quality of Life (LQI), Argentina: combining socioeconomic and enviromental indicators. In: Indicators of Quality of Life in Latin America, pp. 57-77 [G Tonon, editor]. Switzerland: Springer International Publishing.

27. U.S. National Library of Medicine (NLM) (2021) Medical Subject Headings (MeSH) Database. https://www.ncbi. nlm.nih.gov/mesh/ (accessed August 2021).

28. National Ministry of Health (2020) Dietary Guidelines for the Argentine Population. Buenos Aires: National Ministry of Health of Argentina. https://bancos.salud.gob.ar/recurso/ guias-alimentarias-para-la-poblacion-argentina (accessed August 2021).

29. The IPAQ group (2008) International Physical Activity Questionnaire. http://www.ipaq.ki.se/ (accessed August 2019).

30. National Institute of Statistics and Censuses - I.N.D.E.C. (2019) 4th National Survey of Risk Factors. Definitive results. Autonomous City of Buenos Aires (CABA): INDEC \& National Government Secretary of Health.

31. Sobal J, Rauschenbach BS \& Frongillo EA (1992) Marital status, fatness and obesity. Soc Sci Med 35, 915-923.

32. Manfredini R, De Giorgi A, Tiseo R et al. (2017) Marital status, cardiovascular diseases, and cardiovascular risk factors: a review of the evidence. $J$ Womens Health 26, 624-632.

33. Sobal J, Hanson KL \& Frongillo EA (2009) Gender, ethnicity, marital status, and body weight in the United States. Obesity 17, 2223-2231.

34. Merino Ventosa M \& Urbanos-Garrido RM (2016) Disentangling effects of socioeconomic status on obesity: a cross-sectional study of the Spanish adult population. Econ Hum Biol 22, 216-224.

35. McLaren L (2007) Socioeconomic status and obesity. Epidemiol Rev 29, 29-48.

36. Forbes GB, Jung J, Vaamonde JD et al. (2012) Body dissatisfaction and disordered eating in three cultures: Argentina, Brazil, and the US. Sex Roles 66, 677-694.

37. Haslam SA, McMahon C, Cruwys T et al. (2018) Social cure, what social cure? The propensity to underestimate the importance of social factors for health. Soc Sci Med 198, 14-21.

38. Rodríguez López S, Colantonio SE \& Celton DE (2017) Socioeconomic inequalities in self-reported health and physical functioning in Argentina: findings from the National Survey on Quality of Life of older adults 2012(ENCaViAM). J Biosoc Sci 49, 597-610.

39. Harrington DW \& Elliott SJ (2009) Weighing the importance of neighbourhood: a multilevel exploration of the determinants of overweight and obesity. Soc Sci Med 68, 593-600.

40. Kim TJ, Roesler NM \& von dem Knesebeck O (2017) Causation or selection - examining the relation between education and overweight/obesity in prospective observational studies: a meta-analysis. Obes Rev 18, 660-672.

41. Zapata ME, Soruco AI \& Carmuega E (2020) Malnutrition in all its forms and socio-economic indicators in Argentina. Public Health Nutr 23, s13-s20.
42. Curi-Quinto K, Ortiz-Panozo E \& López de Romaña D (2020) Malnutrition in all its forms and socio-economic disparities in children under 5 years of age and women of reproductive age in Peru. Public Health Nutr 23, s89-s100.

43. Perez Ferrer C, McMunn A, Rivera Dommarco JA et al. (2014) Educational inequalities in obesity among Mexican women: time-trends from 1988 to 2012. PLOS ONE 9, e90195.

44. Chung W \& Kim R (2020) A reversal of the association between education level and obesity risk during ageing: a gender-specific longitudinal study in South Korea. Int $J$ Environ Res Public Health 17, 6755.

45. Wardle J, Waller J \& Jarvis MJ (2002) Sex differences in the association of socioeconomic status with obesity. Am J Public Health 92, 1299-1304.

46. Michou M, Panagiotakos DB \& Costarelli V (2018) Low health literacy and excess body weight: a systematic review. Cent Eur J Public Health 26, 234-241.

47. Friel S, Akerman M, Hancock T et al. (2011) Addressing the social and environmental determinants of urban health equity: evidence for action and a research agenda. J Urban Health 88, 860-874.

48. Fleischer NL, Diez Roux AV, Alazraqui M et al. (2011). Socioeconomic gradients in chronic disease risk factors in middle-income countries: evidence of effect modification by urbanicity in Argentina. Am J Public Health 101, 294-301.

49. Darmon N \& Drewnowski A (2015) Contribution of food prices and diet cost to socioeconomic disparities in diet quality and health: a systematic review and analysis. Nutr Rev 73, 643-660.

50. Oliveira DM, Marques ML, Dos Santos D et al. (2020) Spatial index relating urban environment to health lifestyle and obesity risk in men and women from different age groups. PLoS One 15, e0229961.

51. World Health Organization (2008) Our Cities, Our Health, Our Future: Acting on Social Determinants for Health Equity in Urban Settings. Report to the WHO Commission on Social Determinants of Health from the Knowledge Network on Urban Settings. Geneva: WHO.

52. Lachowycz K \& Jones AP (2011) Greenspace and obesity: a systematic review of the evidence. Obes Rev 12, e183-e189.

53. Villeneuve PJ, Jerrett M, Su JG et al. (2018). Association of residential greenness with obesity and physical activity in a US cohort of women. Environ Res 160, 372-384.

54. Devarajan R, Prabhakaran D \& Goenka S (2020) Built environment for physical activity-An urban barometer, surveillance, and monitoring. Obes Rev 21, e12938.

55. MacBride-Stewart S, Gong Y \& Antell J (2016) Exploring the interconnections between gender, health and nature. Public Health 141, 279-286.

56. Sander HA, Ghosh D \& Hodson CB (2017) Varying age-gender associations between body mass index and urban greenspace. Urban For Urban Green 26, 1-10.

57. Drewnowski A, Buszkiewicz J, Aggarwal A et al. (2020) Obesity and the built environment: a reappraisal. Obesity 28, 22-30.

58. Tung EL, Cagney KA, Peek ME et al. (2017) Spatial context and health inequity: reconfiguring race, place, and poverty. J Urban Health 94, 757-763.

59. Howe LD, Galobardes B, Matijasevich A et al. (2012) Measuring socio-economic position for epidemiological studies in low- and middle-income countries: a methods of measurement in epidemiology paper. Int J Epidemiol $\mathbf{4 1}$, 871-886. 